\title{
Patients' Perspectives of the Health Worker-patient Relationship in Cape Coast Metropolis, Ghana
}

\section{Kofi Tekyi Asamoah}

Komfo Anokye Teaching Hospital

\section{Emmanuel Appiah-Brempong}

Kwame Nkrumah University of Science and Technology

HASEHNI VAMPERE ( $\nabla$ vamperehassan@gmail.com )

Kwame Nkrumah University of Science and Technology College of Health Sciences

https://orcid.org/0000-0002-8012-6150

\section{Research note}

Keywords: Health worker-patient relationship, patient-centred approach, explanation, information, preventive health, interaction, control

Posted Date: July 17th, 2019

DOI: https://doi.org/10.21203/rs.2.11526/v1

License: (1) (1) This work is licensed under a Creative Commons Attribution 4.0 International License. Read Full License 


\section{Abstract}

Objective: The importance of good interactions between health workers and patients cannot be overemphasised. It calms troubled patients and allows them access to all pertinent information to ensure good health. However, some patients are harshly treated, compelling them to withhold sensitive and relevant information whiles others are given very little education on preventive health practices, hampering their preventive health practice. This study aimed to assess the health worker-patient relationship from the patients' perspective and its effect on preventive health practices in the Cape Coast Metropolis, Ghana. Results: About $70 \%$ of patients were satisfied with how they are related to in hospital as $93.8 \%$ were allowed to express themselves freely without interruption by the doctor, though $22.7 \%$ believed they were not examined by the doctor. $53.1 \%$ of the participants were given explanations of their ailments, with $64.4 \%$ receiving information on how to prevent complications and recurrences. $70.7 \%$ left the consultation with a sense of control over personal health events. Below $50 \%$ were educated on intervention procedures, treatment regimens and side effects of their drugs. Generally, patients showed satisfaction with their interactions with health workers.

\section{Introduction}

The importance of health, as a need for all and not a want [1], requires good relations between health workers and patients, as it is necessary for the success of the medical consultation, which is used as a measure of efficiency [1]. Good health refers to physical, mental and social well-being [2] at all times, highlighting the need for a holistic approach to healthcare delivery, with due consideration for the psychosocial disposition of the individual. Poor interpersonal relations lead to problems with compliance and inhibit patient education, affecting preventive health practices [3-5]. A cordial relationship between health workers and patients is thus imperative for an adequate exchange of information [6].

That notwithstanding, Andersen (2004), in a study on Ghanaian hospitals, reported that patients are sometimes abused verbally and even physically when they "disobey" health workers' instructions [7]. This may sometimes result in patients withholding information that may be vital to accurate diagnosis and management, potentially increasing morbidity.

This shows that it is not satisfying enough to concern oneself solely with the availability and supply of healthcare services to the population, but also the manner in which these services are offered $[1,3,4]$ to allow health workers adequately educate patients as agents of behaviour change [8]. The Ghanaian medical consultation is however paternalistic [9], and minimally involves patients [10].

Though patients are encouraged to take initiative and seek advice [12], Longo et al. (2010) showed that information seeking is conceptual; patients seek information on what they 
think is important at that particular point in time [13].

Other studies showed a direct relation between understanding and health seeking behaviour $[5,14]$. Patients briefed on hospital proceedings, including examination findings, tend to develop trust in the physician [5]. Thus, it is important to assess the patient-health worker relationship for enhanced interraction.

\section{Methods}

\section{Study area}

The study was conducted in the Cape Coast Metropolis, Ghana. There are a number of government and private health facilities in the Metropolis. At the district level, there are 5 health sub-districts; Ewim, Adisadel, Efutu, Cape Coast RCH Central and University. The University Hospital supplements health services at this level. At the metropolitan level, Cape Coast is served by the Cape Coast Metropolitan Hospital and the Central Regional Hospital, which serves as a Regional referral hospital. The study was specifically conducted at the Adisadel Health Centre, University Hospital and the Cape Coast Metropolitan Hospital.

\section{Study design}

The researcher used a descriptive case study design and quantitative methods to evaluate the interaction between health workers and patients by measuring specific parameters.

\section{Sample size calculation}

Using the EpiInfo ${ }^{\mathrm{TM}}$ software with the population size of 169,894 , confidence level of $95 \%$ and prevalence of $50 \%$ (this was assumed as the percentage of residents who attend hospital for medical attention was unknown), the calculated sample size was 384 .

\section{Research instruments}

An observational check-list and questionnaire were used to collect the data.

The questionnaire contained sections on demographic information of respondents, frequency of hospital visits and factors determining patients' choice of hospital, interaction between workers in various hospital departments and patients' insight into treatment given (if applicable), and preventive health practices. 
The observational checklist was designed to present a first-hand feel of proceedings in the hospital and objectively assess what transpired in all the departments of interest. It comprised four categories, each with different parameters that were either ticked 'yes' or 'no'. The categories were records, nurses, doctors and laboratory staff.

\section{Data collection procedure}

An exit interview was used in three of the health centres under the jurisdiction of the Metropolitan Health Directorate to sample respondents using a convenient sampling method.

For respondents who appeared too ill, too young or too old, the questionnaires were filled by the person who escorted them to the hospital and was with them through all the relevant stations. Respondents who could read and write filled the questionnaires personally.

Proceedings in the health centres were also observed on 5 of the days, selected randomly by ballot. An hour was spent at each station and responses ticked based on what happened in $50 \%$ of the encounters during the period of observation. Health workers at those stations were informed that their activities were just being observed. The purpose for the study was however not disclosed to them at the time of observation. This was to prevent any changes in the normal attitude which may have affected the reliability of the findings.

\section{Data analysis techniques}

Data collected through the questionnaire was coded and managed with the help of data analysis software SPSS (version 16), for both open and closed questions.

After coding and entry, the data, frequencies, percentages, pie charts, bar and line graphs, were generated with the help of SPSS and Microsoft Excel to help understand and establish the data. Cross tabulation and correlation were also employed to help understand and establish the relationship between specified variables.

\section{Results}

\section{Observations}


Interaction with patients was courteous in all departments on most of the days. Courtesy, as used above, refers to a means of communicating in which the receiver feels treated with respect. Personnel began the interaction with a greeting and spoke in low tones. There were, however, isolated incidents where there were misunderstandings between both parties.

Patients were not interrupted as they spoke, and doctors used open questions to understand what the patients were coming in with. A few patients, notably those with acute conditions like gastroenteritis and malaria, were counselled on practices to prevent recurrence of these conditions.

Interaction between laboratory staff and patients was usually indifferent, with patients being instructed on what to do without any greeting. After sitting down, the next instruction was to ask the patient to stretch his/her hand, without offering any explanation for the procedure going to be carried out. When patients were in pain, however, the staff apologised for the pain and consoled the patients.

\section{Questionnaires}

A total of 384 questionnaires were administered to people across all age groups, with a $100 \%$ response rate. The results are presented below.

\section{Table 1 Demographic information of respondents}




\begin{tabular}{|l|l|l|}
\hline Characteristic & Frequency & Percentage \\
\hline & & \\
\hline Age & & \\
\hline Below 18 & 37 & 9.6 \\
\hline $18-30$ & 207 & 53.9 \\
\hline $31-40$ & 46 & 12.0 \\
\hline $41-50$ & 16 & 4.2 \\
\hline $51-60$ & 32 & 8.3 \\
\hline Above 61 & 46 & 12.0 \\
\hline & & \\
\hline Gender & & \\
\hline Male & 177 & 46.1 \\
\hline Female & 207 & 53.9 \\
\hline & & \\
\hline Highest educational level & & \\
\hline No formal education & 18 & 4.7 \\
\hline Basic & 125 & 32.6 \\
\hline Secondary & 81 & 21.1 \\
\hline Tertiary & 160 & 41.7 \\
\hline & & \\
\hline Marital status & & \\
\hline Married & 118 & 30.7 \\
\hline Single & 222 & 57.8 \\
\hline Divorced & 6 & 1.6 \\
\hline Separated & 5 & 1.3 \\
\hline Cohabitation & 4 & 1.0 \\
\hline Widowed & 29 & 7.6 \\
\hline & & \\
\hline Occupation & & \\
\hline Self-employed & 118 & 30.7 \\
\hline Unemployed & 86 & 22.4 \\
\hline Civil servant & 61 & 15.9 \\
\hline Private sector employee & 119 & 30.9 \\
\hline & & \\
\hline & & \\
\hline & & \\
\hline & & \\
\hline & & \\
\hline & & \\
\hline & & \\
\hline & & \\
\hline & & \\
\hline & & \\
\hline & & \\
\hline & & \\
\hline & & \\
\hline & & \\
\hline & & \\
\hline & & \\
\hline
\end{tabular}

$63.5 \%$ of respondents were between the ages of 18 and 30.

46.1\% were males whereas $53.9 \%$ were females, with $41.7 \%$ of respondents having had tertiary education, $32.6 \%$ had basic education, $21.1 \%$ had secondary education, and $4.7 \%$, no education.

57.8\% were single and $30.7 \%$ married. $9.9 \%$ were widowed, divorced, separated or cohabitating.

$77.6 \%$ of respondents were employed in both public and private jobs. The remaining $22.4 \%$ were unemployed, predominantly students or retirees. 


\section{Conduct of health workers}

Most health workers were judged to be warm and courteous with the lowest number recorded by the laboratory department (68.6\%). $7 \%$ of respondents reported being treated harshly by records personnel. $73.2 \%$ said nurses educated them on the hospital procedure.

Procedures were explained to respondents by requesting from physicians in $44.6 \%$ of the cases, whereas $55.4 \%$ of respondents received no explanation before the procedure was carried out. $70.5 \%$ were however consoled by laboratory workers during painful procedures.

\section{The medical consultation}

93.8\% were allowed to express themselves freely without being unduly interrupted by the doctor, though $22.7 \%$ said they were not examined by the doctor. Components of examination included touching them to feel for warmth, assessing for pallor and use of the stethoscope.

Only $37.3 \%$ of the respondents were told what their diagnoses were, though $53.1 \%$ received explanations for their pathologies without being told its name. Of those who knew their diagnoses, $51.7 \%$ were informed of long-term diagnoses, including pregnancy, hypertension, sickle cell disease, diabetes mellitus, osteoarthritis. The remaining $48.3 \%$ had acute diagnoses like malaria, typhoid, food poisoning, etc. $52 \%$ of respondents were not informed of their diagnoses.

For $46 \%$ of respondents, treatment and treatment options were discussed with the respondents, which was not the case with $54 \%$ of respondents.

$75.8 \%$ of respondents underwent procedures, including lab tests, ECGs, x-rays, and ultrasound scans, of which $45.7 \%$ were given explanations on the procedure to be carried out by the requesting officer.

$64.4 \%$ said they had been given an explanation on how to prevent recurrence or complications of their diagnoses, whilst $70.7 \%$ of respondents reported having a sense of control over personal health events as a result of the consultation.

\section{Discussion}

\section{Interaction with health workers}

Respondents were generally satisfied with the nature of their interaction with all health workers. Interaction with health workers is a major source of patient satisfaction with 
health services and a measure of health workers' efficiency [1]. Some respondents however said when they attended hospital in the afternoons, health workers were more irritable than when they went in the mornings.

\section{The medical consultation}

Respondents were encouraged to narrate their problems to the doctor freely and whatever questions they asked were answered. This contradicts Norman et al.'s (2011) conclusion on the medical interview process being paternalistic in Ghana [9]. These patients will therefore understand whatever condition they have, helping them maintain good health in the future. Patients expressed satisfaction with the consultation, which can be attributed it to their ability to talk freely about their health concerns.

Patients' experiences of the hospital visit were enhanced when doctors "touched" them to examine and told them their findings, corroborating findings from studies in Nigeria [5]. Such patients are likely to feel more thoroughly attended to than those who were not examined as expected. Indeed, a few respondents complained that they were not examined in any way, especially those accompanying children and the elderly because of their perception about what constitute examination.

For participants who required investigative procedures, including lab tests, electrocardiography, x-ray scans etc, most had no idea what was going to be done. This raises questions about whether or not informed consent was truly sought, as adequate information prior to consent is required for it to be considered informed. Such patients are unlikely to be able to give related information to other healthcare workers in the future.

During the observational periods, it was found that though most of the patients were examined by the doctors, they were not informed of their diagnoses, given explanations for the condition they presented with, nor educated on the treatment regimen.

Contrary to this observation, data from the study showed that many of the participants were given explanations for their conditions. This may be because of the high educational level among respondents, as shown in Table 1. In spite of this, majority were not given any information on the treatment being given, or treatment options (if any). The lack of information on treatment may lead to people defaulting or overdosing their medications [3, $5,11]$.

Respondents understood their diagnoses because the doctor had explained it to them and corrected misconceptions they had. This, as stated by Longo et al. (2010), is a very important part of the medical consultation [13].

Some respondents received explanations for their conditions and, therefore, understood the condition but did not know the name of the ailment. Though $71.8 \%$ and $75.3 \%$ of those with 
long term and acute diagnoses, respectively, received an explanation on how to prevent complications, a correlation coefficient of 0.027 was however found between being told the name of the diagnosis and receiving information on preventive health, suggesting a mild positive relationship. This is contrasted with correlation coefficient of 0.577 between explanation of a diagnosis and information on how to prevent complications, proving a strong direct relationship between the two. Thus, explanations for presenting conditions are more likely to lead to patients learning to practice preventive health by gaining control over modifiable risk factors than just telling them their diagnoses. This may be because, as patients ask questions, understanding of their ailments is deepened [5, 13].

\section{Limitation}

These is the possibility of changed behaviour on the side of the hospital staff during the observation as they were told they are being observed. Other behaviours might have also been under look or missed especially when the has to move to a different unit.

\section{Declaration}

Ethics approval and consent to participate: Ethical approval was obtained from the research department of the Komfo Anokye Teaching Hospital (KATH) in Kumasi, Ghana. All the directors at the various hospitals where the data was collected received written notice and has further approved the study.

Participants consent to participate was also sought. After explaining the purpose of the study to them and assure them of confidentiality, a consent form was given to each participant to be completed as a confirmation of their consent to participate. Those who do not sign to the consent form were not involved.

Consent for publication: Not Applicable

Availability of data and materials: The datasets used and/or analysed during the current study are available from the corresponding author on reasonable request. This dataset is with the corresponding author and can be provided when requested.

Competing interests: All authors declared that there is no competing interest.

Funding: There was no external funding for the study. Funding was from authors' contributions.

Authors' contribution: EA-B designed the tools for data collection and supervised all steps in the entire study. KTA initiated the study, wrote background information and collected data by observational and partly by questionnaire. VH partly collected the data using 
questionnaire and analysed the data with support from KTA and wrote out the manuscript. All authors read and approved the final manuscript.

Acknowledgments: The authors acknowledged the research department of the Komfo Anokye Teaching Hospital, Kumasi - Ghana, for granting ethical approval for the study to be conducted and also the medical directors of Adisadel Urban Health Centre, University Hospital and the Cape Coast Metropolitan Hospital for allowing the study to be conducted in their hospitals.

\section{References}

1. BendapudiNM, BerryLL, Frey AK, Parish JT\& Rayburn WL. Patient Perspectives On Ideal Physician Behaviours. Mayo Clin. Proc.2006, 81:338-344.

2. World Health Organization. Official Records Of The World Health Organization. Preamble To The Constitution Of The World Health Organisation As Adopted By The International Health Conference, 1946, 2:100.

3. Ferguson WJ\& Candib LM. Culture, Language And The Doctor-Patient Relationship. Modern Culture And Physician-Patient Communication2002, 34:353-361.

4. Bakic-Miric NM\& Bakic NM. Successful Doctor-Patient Communication And Rapport Building As The Key Skills Of Medical Practice. Medicine And Biology2008, 15:74-79.

5. Iyalomhe GBS\& Iyalomhe SI. Health Seeking Behaviour Of Rural Dwellers In Southern Nigeria:Implications For Healthcare Professionals. International Journal Of Tropical Disease And Health2012, 2:62-71.

6. Goold SD\& Lipkin Jr M.The Doctor-Patient Relationship; Challenges, Opportunities And Strategies. Journal Of General Internal Medicine1999, 14:S26-S33.

7. Andersen HM. "Villagers". Differential Treatment In A Ghanaian Hospital. Social Science And Medicine2004, 59:2003-2012.

8. Wolff LS, Massett HA, Weber D, Mockenhaupt RE, Haasmiller S \& Maibach EW.Opportunities And Barriers To Disease Prevention Counselling In The Primary Care 
Setting:A Multisite Qualitative Study With Us Health Customers. Health Promotion International2010,25:265-276.

9. Norman ID, Aikins MK\& Binka FN. Ethics And Electronic Health Information Technology:Challenges For Evidence-Based Medicine And The Physician-Patient Relationship. Ghana Medical Journal2011, 45:115-124.

10. Morgan M. The Doctor-Patient Relationshipin Scambler G (editor), Sociology As Applied To Medicine, $6^{\text {th }}$ edition. London: Saunders, 2008. pp. 55-70.

11. Thompson D \& Ciechanowski PS. Attaching A New Understanding To The PhysicianPatient Relationship In Family Practice.Journal Of The American Board Of Family Practice2003, 16:219-226.

12. Ghana Health Service. The Patients Charter. http://www.ghanahealthservice.org/aboutus (accssed 26th December, 2013).

13. Longo DR, Schubert SL, Wright BA, Lemaster J, Williams CD\& Clove JN. Health Information Seeking, Receipt And Use In Diabetes Self-Management. Annals Of Family Medicine2010, 8:334-340.

14. Owusu AY\& Adamba C. Household Perceptions, Treatment-Seeking Behaviour And Health Outcomes For Buruli Ulcer Disease In A Peri-Urban District In Ghana.Advances In Applied Sociology2012, 2:179-186. 